\title{
Morphometric and Topographic Study of Coronary Ostia
}

\author{
Jennecy Sales Cavalcanti, Natália Corrêa Vieira de Melo, Renata Simões de Vasconcelos \\ Recife, PE - Brazil
}

Objective - To investigate the morphometric and topographic aspects of coronary ostia, correlating them with the aortic leaflets.

Methods - Fifty-one hearts with the great vessels attached were analyzed in this study. The ascending aorta was transversally sectioned $1 \mathrm{~cm}$ above the commissures of the aortic leaflets. The right and left coronary ostia were analyzed, as were the distances from these ostia to the bottom of the aortic sinuses and to the commissures of the aortic leaflets.

Results - The left coronary ostium was located below the intercommissural line in $42 \%$ of cases, above that line in $40 \%$ of cases, and at the level of that line in 18\% of cases. The mean distance from the left coronary ostium to the bottom of the corresponding sinus was $12.6 \pm 2.61 \mathrm{~mm}$. The right coronary ostium was located below the intercommissural line in $60 \%$ of cases, above that line in $28 \%$ of cases, and at the level of that line in $12 \%$ of cases. The mean distance from the right coronary ostium to the bottom of the corresponding aortic sinus was $13.2 \pm 2.64 \mathrm{~mm}$. The mean diameters of the left and right coronary ostia were $4.75 \pm 0.93 \mathrm{~mm}$ and $3.46 \pm 0.94 \mathrm{~mm}$, respectively. The mean diameters of the juxtamural portion of the left and right coronary arteries were $3.75 \pm 0.79 \mathrm{~mm}$ and $2.9 \pm 0.73 \mathrm{~mm}$, respectively. In one case, both ostia were located in the left coronary sinus.

Conclusion - The left coronary ostium may be located either above or below the intercommissural line. The right coronary ostium is predominantly located below the intercommissural line. The coronary ostia have reduced diameters as compared with the juxtamural diameters of their respective coronary arteries.

Key words: coronary artery, aortic valve, heart

Universidade Federal de Pernambuco, Recife

Mailing address: Jennecy Sales Cavalcanti - Rua Félix de Brito Melo, 912/501

Cep 51020-260 - Recife, PE, Brazil - E-mail:

English version by Stela Maris C. e Gandour
The great importance of coronary catheterization for diagnostic and therapeutic purposes has currently motivated several studies on the anatomic position of coronary ostia. In most investigations, 2 coronary ostia, one right and one left, were observed located in the 2 aortic sinuses (sinuses of Valsalva) closer to the pulmonary trunk ${ }^{1-6 .}$

Adequate irrigation of the heart depends fundamentally on the good morphological conditions of the right and left coronary arteries. These arteries have the peculiarity of being the only ones filled during the diastolic phase of cardiac rhythm. For this to happen properly, some conditions, such as anatomic integrity of the aortic valve, absence of valvular malformations and anatomic malformations of the coronary arteries that result in a reduction in blood flow to the myocardium, are required ${ }^{7-15}$.

Other factors may be involved in the possible reduction in coronary blood flow, such as variations in the position of the coronary ostia in relation to the aortic leaflets and the diameter of the ostia ${ }^{16-19}$.

Considering the hypotheses formulated by these authors that changes in coronary flow may be due to changes in diameter, position, and anatomic relations of the coronary ostia, this study aimed at investigating these factors, emphasizing their possible implications in functional order.

\section{Methods}

Fifty-one hearts with their great vessels attached and fixed in $10 \%$ formalin were used in this study. This autopsy material originated from white and nonwhite adults of both sexes, whose cause of death was not heart disease, from the Department of Anatomy of the Center of Biological Sciences of the Federal University of Pernambuco (UFPE).

The hearts were dissected, the pericardium involving the root of the aorta was removed, and the origin of the right and left coronary arteries was isolated. Then, the ascending aorta was transversally sectioned approximately $1 \mathrm{~cm}$ above the commissures of the aortic leaflets. Next, the aorta was longitudinally opened at the level of the posterior aortic sinus (noncoronary sinus) to enable the visualization and analysis of the right and left aortic leaflets and their respective coronary ostia. In addition, the coronary arteries were sectioned at the level of their origins in the aortic wall (juxtamural portion of the coronary arteries). 
The coronary ostia in relation to the right and left aortic leaflets were identified and, with the aid of a millimeter ruler and a pachymeter, the following measurements were taken: the diameters of the coronary ostia, the diameters of the juxtamural portion of the coronary arteries, and the distance from the coronary ostia to the bottom of the aortic sinus and to the commissures of the aortic leaflets. To measure these parameters, one extremity of the pachymeter was placed in the median region of the ostium and the other extremity was displaced to the bottom of the aortic sinus, and then, to the commissure to the left of the ostium and to the right of the same ostium. The values found in each measurement were listed in tables and statistically analyzed.

The relation of the coronary ostia with the intercommissural line was also observed, and the hearts were grouped according to the following parameters: ostium above the intercommissural line, below the intercommissural line, and at the level of the intercommissural line.

\section{Results}

All hearts studied had trileaflet aortic valves. In 50 of the 51 hearts studied, the coronary arteries originated from the respective aortic sinuses; in one of the hearts, however, both arteries originated from the left aortic sinus. Data obtained from the latter heart were not included in the calculation of the means of the results in this study. No isolated nourishing artery of the right ventricular infundibulum (conus artery) was observed.

The relation between the location of the left and right coronary ostia and the intercommissural line in each heart is shown in table I. Figure 1 depicts the coronary ostia located below and at the level of the intercommissural line.

The results of the measurements of the distances from the left and right coronary ostia to the commissures located to the right and left of the referred ostia are shown in table II. Considering this same table, on average, the left coronary ostium was located in the central region of the corresponding aortic sinus, while the right coronary ostium was displaced to the right in the respective aortic sinus.
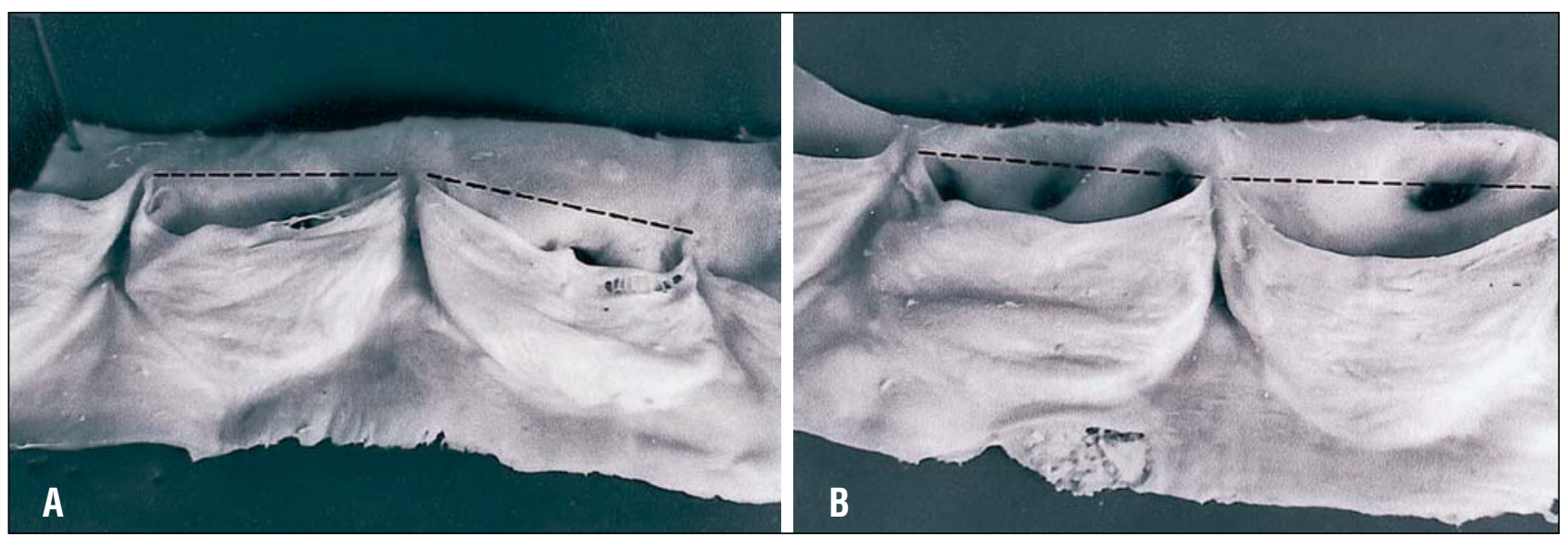

Fig.1 - Fhotograph of the aortic valve showing the location of the coronary ostia in regard the intercommissural line. A: right and left ostia below the intercommissural line; B: right and left ostia at the level of the intercommissural line. 


\begin{tabular}{|c|c|c|c|}
\hline \multicolumn{4}{|c|}{$\begin{array}{l}\text { Table II - Mean values of the distances between the coronary ostia and } \\
\text { the commissures of the aortic leaflets ( } \mathrm{mm})\end{array}$} \\
\hline $\begin{array}{l}\text { Coronary } \\
\text { ostium }\end{array}$ & Comissure & Mean distance & $\begin{array}{c}\text { Mean point of the } \\
\text { intercommissural } \\
\text { distance }\end{array}$ \\
\hline Left & $\begin{array}{l}\text { Commissure to the left } \\
\text { Commissure to the right }\end{array}$ & $\begin{array}{l}11.5 \pm 3.64 \\
11.2 \pm 2.56\end{array}$ & 11.3 \\
\hline Right & $\begin{array}{l}\text { Commissure to the left } \\
\text { Commissure to the right }\end{array}$ & $\begin{array}{l}14.7 \pm 3.28 \\
10.4 \pm 3.44\end{array}$ & 12.5 \\
\hline
\end{tabular}

\begin{tabular}{|lcccc|}
\hline \multicolumn{5}{|c|}{$\begin{array}{c}\text { Table III - Diameters of the coronary ostia and the roots of the } \\
\text { corresponding coronary arteries (mm) }\end{array}$} \\
\hline $\begin{array}{l}\text { Coronary } \\
\text { artery }\end{array}$ & $\begin{array}{c}\text { Diameter of } \\
\text { the ostium }\end{array}$ & $\begin{array}{c}\text { Diameter of } \\
\text { the root }\end{array}$ & $\begin{array}{c}\text { Mean } \\
\text { reduction (mm) }\end{array}$ & $\begin{array}{c}\text { Percentage of } \\
\text { reduction }\end{array}$ \\
\hline Right & $3.46 \pm 0.93$ & $2.9 \pm 0.74$ & $0.55 \pm 0.44$ & $16 \%$ \\
Left & $4.25 \pm 0.94$ & $3.75 \pm 0.8$ & $0.51 \pm 0.59$ & $11 \%$ \\
\hline
\end{tabular}

and left leaflets of the aortic valve ${ }^{1-6}$. In our case series, only 1 heart did not fit into the above cited pattern, having the 2 ostia at the level of the left aortic sinus. This variation was also found in 1 of the 100 hearts studied by Jatene et $\mathrm{al}^{16}$.

Previous studies emphasize the limitations in the measurements of cardiac valves during autopsy, because a certain degree of retraction and stiffness of the structures analyzed always exists, due to the rigor mortis and the fixation process ${ }^{20}$. However, Tei et al ${ }^{21}$ compared 3 groups of materials and observed similar values in hearts not fixed in formalin, hearts fixed in formalin, and hearts assessed on echocardiograms. Similar results have also been reported by Scholz et al ${ }^{22}$ and Maron et al ${ }^{23}$ when studying cardiac mass, valvular circumferences, and ventricular thickness.

Of the 100 ostia analyzed in the present study, $51 \%$ were located below the intercommissural line, $34 \%$ above it, and $15 \%$ at its level, ie, 25 of the 50 hearts analyzed had 1 or both ostia above the intercommissural line. These results are similar to those of Vlodaver et $\mathrm{al}^{6}$ who reported that 22 of 50 hearts studied had 1 or both ostia above the intercommissural line. On the other hand, our results do not agree with those obtained by Turner and Navaratnam, ${ }^{1}$ who found $16 \%$ of the ostia above the intercommissural line, and with the results obtained by Muriago et al, ${ }^{18}$ who found only $13 \%$ of the ostia above that line.

In regard to the left coronary ostium, our results differ from those by Muriago et al, ${ }^{18}$ who reported a left coronary ostium below the intercommissural line in $60 \%$ of their case series, above that line in $22 \%$, and at the level of the intercommissural line in $9 \%$. In regard to the right coronary ostium, these same authors reported that the right coronary ostium was below the intercommissural line in $78 \%$ of their case series, above that line in $13 \%$, and at the level of that line in $9 \%$. Our findings also differ from those reported by these authors regarding the location of both ostia in each heart. According to their study, both ostia were below the intercommissural line in $57 \%$ of cases, and both ostia were above that line in only $9 \%$ of cases.
Turner and Navaratnam ${ }^{1}$ reported that from the functional point of view it would be advantageous that both coronary ostia were above the intercommissural line, which, according to the authors, would make the coronary blood flow easier during ventricular systole and would also prevent the obstruction of the ostia when the aortic valve was opened. We do not agree with these authors, because it is well known in cardiac physiology that blood flows to the coronary arteries mainly during the diastolic phase of the cardiac cycle.

The studies by Muriago et al ${ }^{18}$ indicated that the coronary ostia are not located in the center of each aortic sinus, but, on the contrary, they are displaced to the commissure located to the right of the ostia. Their results are similar to ours in regard to the location of the right coronary ostium; however, it is worth emphasizing that, in our material, the left coronary ostium was located almost in the central region of the corresponding aortic sinus, which is in accordance with the studies reported by Turner and Navaratnam ${ }^{1}$ and McAlpine ${ }^{24}$. Our results showed that, on average, the right coronary ostia are located in the right side of the corresponding aortic sinus, in contrast with the findings of Turner and Navaratnam, ${ }^{1}$ who reported that both coronary ostia are located in the central region of their respective aortic sinuses.

McAlpine ${ }^{24}$ proposed that the location of the right coronary ostium in the right half of the corresponding aortic sinus is appropriate, because the right coronary artery is destined to pass around the tricuspid valve, therefore having a more direct course than if it originated in the left or medial portion of the sinus. According to that author, displacement of the left coronary ostium to the right would be more appropriate because the anterior and left parts of the heart are supplied by the left coronary artery. Still regarding this same point, Muriago et a ${ }^{18}$ added that the more central location of the left coronary ostium is justified, because, after its origin, the left coronary artery heads to the space between the pulmonary trunk and the left auricle, branching right after that.

No previous relevant studies on the diameters of the coronary ostia and the juxtamural portions of the coronary arteries have been found nor have records of the correlation between these 2 measurements. We observed that, in $76 \%$ of our sample, the diameter of the left coronary ostium was greater than that of the right coronary ostium, and, in $82 \%$ of cases, the diameter of the juxtamural portion of the left coronary artery was greater than that of the right coronary artery.

We believe that these data are important for clinical and surgical practice, because it is well known that changes in coronary flow may be caused by modifications in the diameter, position, and anatomic relations of the coronary ostia.

In conclusion, we observed that, after studying the parameters described, the left coronary ostium is more medially located in regard to the intercommissural distance than the right coronary ostium, which is displaced to the right side. In regard to the intercommissural line, most coronary ostia were located below the intercommissural line or level 
with it. The diameters of the left coronary ostium and of the left juxtamural portion of the coronary artery were greater than those of the right coronary ostium and of the right jux- tamural portion of the coronary artery. The diameters of the coronary ostia are smaller than those of the respective juxtamural portions of the coronary arteries.

\section{References}

1. Turner K, Navaratnam V. The positions of the coronary arterial ostia. Clin Anat 1996; 9: 376-80.

2. Anderson RH, Becker AE. An Integrated Text and Colour Atlas. London: Churchill Livingstone 1980.

3. Navaratnam V. Design of heart valves: a review. Clin Anat 1993; 6: 327-32.

4. Reid K. The anatomy of the sinus of Valsalva. Thorax 1970;25:79-85.

5. Roberts JP. Arteries, veins and lymphatic vessels of the heart. In A.A. Luisada (ed.) Development and Structure of the Cardiovascular System Chapter 6. New York: McGraw Hill 1961.

6. Vlodaver Z, Neufield HN, Edwards JE. Coronary Arterial Variations in the Normal Heart and in Congenital Heart Disease. New York: Academic Press 1975.

7. Choo SJ, Mcrae G Olomon JP, et al. Aortic root geometry: pattern of differences between leaflets and sinuses of Valsalva. J Heart Valve Dis 1999; 8: 407-15.

8. Yacoub MH, Kilner PJ, Birks EJ, et al. The aortic outflow and root: a tale of dynamism and crosstalk. Ann Thorac Surg 1999; 68(suppl): S37-43.

9. Arai AE, Epstein FH, Bove KE, et al. Visualization of aortic valve leaflets using black blood MRI. J Magn Reson Imaging 1999; 10: 771-7.

10. Heusch A, Quagebeur J, Paulus A, et al. Anomalous origin of all coronary arteries from the pulmonary trunk. Cardiology 1997; 88: 603-8.

11. Lerer PK, Edwards WD. Coronary arterial anatomy in bicuspid aortic valve: necropsy study of 100 hearts. Br Heart J 1981; 45: 142-7.

12. Hutchins GM, Nazararian IH, Bulkley BH. Association of the left dominant coronary arterial system with congenital bicuspid aortic valve. Am J Cardiol 1978; 42: 57-9.

13. Johnson AD, Detwiler JH, Charles BH. Left coronaey artery anatomy in patients with bicuspid aortic valves. Br Heart J 1978; 40: 489-93.

14. Gonzales-Angulo A, Reyes HA, Wallace AS. Anomalies of the origin of the co- ronary arteries (special reference to single coronary artery). Angiology 1966; 17: 96-103.

15. Schlesinger MJ,Zoll PM, Wessler S. The conus artery: a third coronary artery. Am Heart J 1949; 38: 823-36.

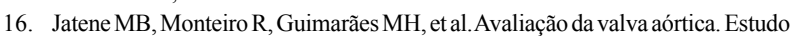
anatômico em 100 corações humanos normais. Arq Bras Cardiol 1999; 73: 75-86.

17. Leguerrier A, Calmat A, Honnart F, et al. Anatomic variation of the aortic coronary openings. Bull Assoc Anat (Nancy) 1976; 60: 721-31.

18. Muriago M, Sheppard MN, Ho SY, et al. Location of the coronary arterial orifices in the normal heart. Clin Anat 1997; 10: 297-302.

19. Brewgr RJ, Deck JD, Capati B, et al. The dynamic aortic root. Cardiovasc Surg 1976; 72: 413-17.

20. Curt HJV, Sanches PCR, Carvalhal SS. Rigor Mortis Cardíaco. Arq Bras Cardiol 1985; 45: 439-46.

21. Tei C, Pilgrim JP, Shah PM, Ormiston JA, Wong M. The tricuspid valve annulus study of size and mottion in normal patients with tricuspid regurgitation. Circulation 1982: 66: 665-71.

22. Scholz DG, Kitzman DW, Hagen PT, Ilstrup DM, Edwards WD. Age-related changes in normal hearts during the first 10 decades of life. Part I: a quantitative anatomic study of 200 specimens from subjects from birth to 19 years old. Mayo Clin Proc 1988; 63: 126-36.

23. Maron BJ, Henry WL, Roberts WC, Epstein SE. Comparison of echocardiographic and necropsy measurements of ventricular wall thicknesses in patients with and without disproportionate septal thickening. Circulation 1997; 55: 341-6.

24. McAlpine WA. Heart and Coronary Arteries: Anatomical Atlas for Clinical Diagnosis, Radiological Investigation, and Surgical Treatment. Berlin: Springer-Verlag 1975, p.134. 